\title{
Mediatización de las dinámicas culturales de las celebridades: el caso de Rosalía en Instagram
}

\section{Mediatization of celebrities' cultural dynamics: the case of Rosalia on Instagram}

\author{
Bravo-Araujo, A., Serrano-Puche, J. y Codina-Blasco, M. ${ }^{1}$ \\ Recibido: 20-04-2021 - Aceptado: 05-08-2021 \\ https://doi.org/10.26441/RC20.2-2021-A3
}

RESUMEN: Este artículo analiza el proceso de mediatización cultural de las celebridades tomando como caso de estudio la auto-presentación en la red social Instagram de la cantante Rosalía (@rosalia. vt). Para ello se ha realizado un doble análisis cuantitativo y cualitativo de las 449 publicaciones que la cantante realiza entre el 1-1-2018 y el 31-7-2020, periodo en que alcanza fama internacional con el lanzamiento del álbum El Mal Querer. El análisis estadístico descriptivo de esta muestra permite determinar los patrones de publicación de la cantante, las categorías a las que asocia su imagen y el uso que hace de las potencialidades de esta red social. El análisis iconológico de la muestra permite determinar los referentes culturales que Rosalía asocia a su imagen, dentro de un contexto globalizado, urbano y de inspiración flamenca. Este estudio concluye que Rosalía aparece como un caso tipo de "celebritización", ya que usa estratégicamente la lógica mediática de las redes sociales como una manera de afianzar su marca personal diversificándola más allá del ámbito de la música.

Palabras clave: mediatización; lógica mediática; Instagram; Rosalía; celebridades.

\begin{abstract}
This article analyses the process of cultural mediatization of celebrities, taking as a case study the self-presentation of the singer Rosalía (@rosalia.vt) on the social network Instagram. For this purpose, a double quantitative and qualitative analysis has been carried out of the 449 publications made by the singer between 1-1-2018 and 31-7-2020, the period in which she achieved international fame with the release of the album El Mal Querer. The descriptive statistical analysis of this sample allows us to determine the singer's posting patterns, the categories to which she associates her image and the use she makes of the affordances of this social network. The iconological analysis of the sample allows us to determine the cultural references that Rosalía associates with her image within a globalized, urban and flamenco-inspired context. This study concludes that Rosalía appears as a typical case of celebritization, as she strategically uses the media logic of social networks as a way of consolidating her personal brand, diversifying it beyond the field of music.
\end{abstract}

Keywords: mediatization; media logic; Instagram; Rosalía; celebrities.

\footnotetext{
${ }^{1}$ Andrea Bravo-Araujo es Magíster en Investigación en Ciencias Sociales y Graduada en Periodismo por la Universidad de Navarra. abravo.6@alumni.unav.es, https://orcid.org/0000-0003-4877-1464

Javier Serrano-Puche es Doctor en Comunicación y Profesor Titular en la Facultad de Comunicación de la Universidad de Navarra, donde es Vicedecano de Ordenación Académica. Su producción científica más reciente se centra en las tendencias en el consumo de noticias, la desinformación en el espacio público digital y en la relación entre los medios de comunicación y las emociones. jserrano@unav.es, https://orcid.org/0000-0001-6633-5303

Mónica Codina-Blasco es Doctora en Filosofía y Profesora Titular de las asignaturas Deontología Periodística y Deontología de la Comunicación Audiovisual en la Facultad de Comunicación de la Universidad de Navarra. Su investigación se centra en el estudio de la Ética de la Comunicación. mcodina@unav.es, http://orcid.org/0000-0003-3378-7308
} 


\section{Introducción}

La consolidación del proceso de digitalización en el siglo XXI ha llevado a los medios de comunicación a evolucionar hacia formas híbridas (Livingstone, 2009), haciéndose una parte fundamental de la vida cotidiana. Este fenómeno de "mediatización" (Hjarvard, 2013) a largo plazo implica transformaciones de prácticas e instituciones. Transformaciones que, según Lundby, "tienen lugar en la interacción entre los cambios en los medios de comunicación y el contexto social, político y cultural, lo que incluye también la transformación de los medios de comunicación" (2014, p. 14).

En este proceso, el papel de los medios se ha acentuado hasta tal punto que las instituciones sociales quedan supeditadas a la lógica mediática (Altheide \& Snow, 1979). En otras palabras, los medios siguen su propio sistema de reglas y la mediatización alude a la necesaria adaptación de los diferentes campos sociales a dichas reglas. Estas reglas conforman la lógica mediática, entendida como "una forma de comunicación; el proceso a través del cual los medios presentan y transmiten información. Los elementos de esta forma incluyen los diversos medios y los formatos utilizados por estos medios. Los formatos consisten, en parte, en la forma en que se organiza el material, el estilo en el que se presenta, el énfasis en las características particulares del comportamiento y la gramática de la comunicación de los medios" (Altheide \& Snow, 1979, p. 10).

Lejos de ser plataformas neutrales, las redes sociales han cambiado a su vez las condiciones y las reglas de la interacción social, creando una lógica mediática diferente a la de los medios tradicionales (Casero-Ripollés et al., 2016; Klinger \& Svensson, 2015; Van Dijck \& Poell, 2013). Se han erigido en nuevos canales para comunicarse, interactuar y explorar la propia identidad. Estas posibilidades aumentan la confianza de los individuos a la hora de mostrar su vida cotidiana y participar de forma continua en las redes sociales (Stepanyan, 2019). Por ello, las plataformas de medios sociales han instituido nuevas formas de comunicación interpersonal, haciendo que la fama se vuelva más accesible y sea practicada por gente común. En paralelo, las celebridades y las figuras públicas recurren a los medios sociales para comunicarse con sus seguidores y fans, constituyendo las redes como herramienta de comunicación principal (Abidin, 2018).

Aunque se han realizado algunas investigaciones sobre las redes sociales y las celebridades, éstas se han centrado principalmente en explorar el contenido de los perfiles con respecto a sus relaciones parasociales (Kim \& Song, 2016; Basilisco, 2019). Sin embargo, el presente estudio evalúa el papel de las celebridades desde la perspectiva de la "celebritización" (Driessens, 2013), entendida como un proceso que capta la naturaleza cambiante de las figuras públicas y que está vinculado al proceso de mediatización antes señalado. Actualmente, las celebridades se han visto obligadas a adaptarse a la lógica mediática de las redes sociales y a crear un espacio interactivo con sus seguidores. De este modo, las dinámicas culturales habituales asociadas a la autopromoción de un artista y a su interacción con las personas que le admiran, hoy en día se enmarcan y están condicionadas por el fenómeno de la mediatización.

\section{Marco referencial}

\subsection{La "celebritización" y la lógica de los medios sociales}

El rápido auge en la primera década de este siglo de plataformas como Facebook, Twitter, LinkedIn, Youtube o Flickr ha convertido las redes sociales en el núcleo de un amplio ecosistema de medios de comunicación conectiva. Estos espacios conviven con los medios tradicionales y conforman un "sistema mediático híbrido" (Chadwick, 2013), en el que las lógicas de ambos medios se entremezclan y coevolucionan. Siguiendo a Van Dijck \& Poell, entendemos por lógica de los medios sociales "los procesos, principios y prácticas a través de los cuales estas plataformas procesan la 
información, las noticias y la comunicación, y más generalmente, cómo canalizan el tráfico social". Éstos, igual que los medios de comunicación de masas, "tienen la capacidad de transportar su lógica fuera de las plataformas que los generan, mientras que sus distintivas estrategias tecnológicas, discursivas, económicas y organizativas tienden a permanecer implícitas o a parecer "naturales" (2013, p. 11).

Desde el punto de vista de las celebridades, las redes sociales han permitido una transición de los medios "representativos" a los medios "presentacionales". Marshall (2015) establece tres categorías que describen la identidad de las celebridades a la hora de presentarse en las redes sociales: 1) el yo público, 2) el yo público-privado y 3 ) el yo íntimo transgresor. El yo público se presenta como la versión oficial o "industrial" del individuo, donde se comunican las fechas de estreno de su obra, apariciones oficiales y actuaciones. En este primer nivel, se encontrarían las páginas web gestionadas por los mánagers. En el segundo nivel, el de yo público-privado, la celebridad se involucra en el uso de las redes sociales, construyendo su identidad a partir de aquello que quieren mostrar a sus seguidores. En el último nivel, la celebridad mostraría, casi sin censura, la verdadera naturaleza de su persona, compartiendo ideas, pensamientos, ideas y aspectos de su vida cotidiana de forma intercomunicativa.

Una celebridad en Internet se crea como "un producto de performance y percepción" (Abidin, 2018:19), siendo la "cotidianidad" la que permite a las celebridades fomentar una relación social basada en un sentido de comunidad y confianza como capital social. Esta característica ha permitido la aparición de influencers, celebridades nativas de internet. A este fenómeno se le ha denominado "celebrificación" (Gamson, 1994; Turner, 2004), como un concepto que identifica la transformación de personas ordinarias y figuras públicas en celebridades (Driessens, 2013).

Mientras la celebrificación estudia los cambios de las celebrities a nivel individual, centrándose en el proceso por el que la gente común y las figuras públicas se convierten en celebridades, la "celebritización" estudia los cambios socioculturales que provocan las celebridades. Entendemos por "celebritización" "un meta-proceso que capta la naturaleza cambiante, así como el arraigo social y cultural de la celebridad, que puede observarse a través de su democratización, diversificación y migración" (Driessens, 2013, p. 641). La democratización se ha dado gracias a plataformas como YouTube o Instagram, que permiten expandir la zona de autopromoción de los artistas. El arraigo de las celebridades se aprecia también en que no solo operan en el ámbito del entretenimiento y los medios de comunicación, sino en que se han diversificado, llegando también a la política, el deporte o los negocios. La migración se manifiesta en el hecho de que "las celebridades utilizan tanto su relativa autonomía como personalidad pública como su condición de celebridad para desarrollar otras actividades profesionales ya sea dentro de su campo original o para penetrar en otros campos sociales" (Driessens, 2013, p. 647).

A su vez, y siguiendo a Driessens (2013), cabe identificar como "fuerzas moldeadoras" de la "celebritización": 1) la mediatización, 2) la personalización y la 3) comercialización. La mediatización es un requisito para la "celebritización", ya que, al ser esencialmente personalidades de comunicación, deben adaptarse a todos los campos sociales mediatizados. En segundo lugar, la personalización como aspecto importante para convertirse en una celebridad va unido a otros aspectos como la individualización, la emoción y la privacidad. Para Turner (2006), en la actualidad se ha dado un "giro demótico", en que las redes sociales han permitido que "la experiencia vivida de lo ordinario" y los asuntos personales se conviertan en espectáculos públicos y temas comerciales. Por último, la comercialización es la tercera fuerza moldeadora de la "celebritización", pues lo que se mercantiliza de una celebridad no es solo su reputación, sino la "forma humana". Es decir, su imagen, su forma de vestir, su estilo... se convierten en una herramienta para crear públicos y mercados a través del respaldo de marcas y productos. 


\subsection{Potencialidades y uso de Instagram por parte de celebridades}

La red social Instagram, lanzada en 2010 por Kevin Systrom y Mike Krieger, se ha situado como una de las plataformas más utilizadas a nivel global, contando actualmente con más de 1.200 millones de usuarios (We are Social \& Hootsuite, 2021). Instagram promueve una constante participación y actividad para conseguir mayor interacción con otros usuarios (Zulli, 2017; Stepanyan, 2019). Esta forma de comunicarse ha ido ganando terreno en las actividades de las celebridades, quienes prefieren llegar a sus fans de manera directa y sin filtros, en lugar de hacerlo a través de los medios tradicionales (Basilisco et al., 2019; Lewis, 2010).

Las redes sociales permiten que las celebridades tengan la oportunidad de conectar directamente con sus seguidores. Este tipo de interacción lleva a los usuarios de las redes a tener una "presencia social", es decir, sus seguidores tienen la percepción de que las celebridades están presentes en sus vidas de forma virtual (Biocca et al., 2003). Esta forma de "presencia social" se ve favorecida por las potencialidades que ofrece la propia plataforma. El "principio de popularidad" que rige las redes sociales no se basa en la calidad de las relaciones, sino en la cantidad de amigos o seguidores que puede tener un usuario (Van Dijck, 2013, p. 13).

Las posibilidades que Instagram ofrece a los usuarios se convierten en una forma de satisfacer sus necesidades personales durante los procesos de socialización en las redes. Esas funciones innovadoras que introduce cada red social son llamadas affordances, que pueden ser tanto tecnológicas (los perfiles, las historias, los hashtags) como paralingüísticas -dar likes, responder a historias, comentar una publicación, etc.- (Seibel, 2019). Las affordances hacen posible la "interacción entre las personas y su alrededor" (Norman, 2013, p. 19).

El concepto affordances fue utilizado originariamente en el campo de la psicología ecológica, y adoptado en estudios sobre diseño (Bucher \& Helmond, 2017). El concepto describe lo que los artefactos materiales, como las tecnologías de los medios de comunicación, permiten hacer a las personas. Estas posibilidades o elementos visuales permiten interactuar con otros usuarios, asignando variedad de interpretaciones a cada acción que se realiza en las redes sociales. Un ejemplo sería los likes de Instagram, el uso de hashtags (\#) o emojis y las acciones de "compartir" o "comentar". Las affordances permiten o limitan los diferentes tipos de prácticas y hábitos comunicativos (Bucher \& Helmond, 2017).

La identidad online se construye a través de las affordances que proporciona cada red social (Seibel, 2019). De tal modo que el usuario delimita la presentación de su propio yo al mundo. Para Marshall (2015), precisamente esta posibilidad de auto presentación sitúa a las celebridades como un referente para otros usuarios: "Lo que hace que las redes estén muy conectadas con las celebridades es que son una producción constitutiva y orgánica del yo. Esa auto-producción es el núcleo de la actividad de las celebridades y ahora sirve como una rúbrica y plantilla para la organización y producción del yo en línea que se ha convertido como mínimo en un componente importante de nuestra presentación de nosotros mismos al mundo" (p. 39).

La producción del yo en las redes sociales se presenta como un fenómeno de interés para la semiótica visual, ya que se construye sobre parejas de oposiciones como las de público/privado y ser/ aparentar, que en las celebridades se pueden observar claramente, puesto que van a la cabeza de una tendencia hacia la transparencia y la proximidad al receptor (Mattei, 2014).

\section{Metodología}

\subsection{Justificación del objeto de estudio: la red social Instagram de la cantante Rosalía}

Para analizar cómo funcionan los procesos de "celebritización" por medio del uso de las redes sociales y de sus potencialidades se ha tomado como caso de estudio la cuenta de Instagram de la 
cantante Rosalía. Esta elección se justifica por el uso estratégico que la cantante ha hecho de esta red social para crear su propia marca, especialmente a partir del lanzamiento de su disco El Mal Querer en noviembre de 2018, con el que ha obtenido fama internacional. Además, Instagram es la plataforma en que se observa mejor la autorepresentación de las celebridades (Mattei, 2014).

Por tanto, las características que presenta Rosalía como artista, su fama internacional, el uso que hace de una rica iconología distinguiéndose de otros autores españoles (Diez 2020), y su presencia estratégica en Instagram como lugar de auto presentación y creación de su propia marca, así como el número de seguidores, justifican el análisis de la identidad que la cantante crea a través de su perfil de Instagram, así como los valores e ideas asociados a ella, y la convierten en un caso de estudio de los procesos de "celebritización".

\subsection{Objetivos y metodología}

Partiendo desde el punto de vista de la mediatización de las relaciones entre una celebridad y sus fans a través de la lógica mediática social, este trabajo toma como caso de estudio la cantante Rosalía para responder a la siguiente pregunta de investigación: ¿Cuáles son las estrategias profesionales, las prácticas y el uso que hace Rosalía de la red social Instagram? En concreto, la investigación persigue dos objetivos específicos:

O1. Analizar y tipificar el uso que hace Rosalía de Instagram, para determinar cómo aprovecha las potencialidades (affordances) y la lógica mediática de la propia red social para construir su imagen personal como celebrity.

O2. Identificar los referentes culturales que usa Rosalía a través de su perfil de Instagram para interactuar con su audiencia, entendiendo que las celebridades tienen capacidad de moldear la cultura a través de su auto-presentación, mediante la cual se convierten en prescriptores de estilos de vida.

Para ello, este estudio hace uso de dos metodologías: una metodología cuantitativa para analizar los patrones de publicación de la cantante y el uso de las potencialidades de Instagram; y una metodología cualitativa que permitirá poner en relación el uso de esas affordances con los referentes culturales que la cantante usa en esta red social.

El análisis descriptivo de la muestra sigue una metodología cuantitativa, que estudia cuatro variables: A. Tipo de publicación, B. Formato de pie de foto, C. Etiquetas y menciones y D. Categorías por temática. La muestra y plantilla de estudio se detallan en el siguiente epígrafe.

En cuanto a la metodología cualitativa escogida, se propone un análisis semiótico visual a un nivel iconológico de las publicaciones de Instagram de Rosalía, que permitirá identificar cuáles son los factores y las connotaciones que inciden en la interpretación de los usuarios. La semiótica visual, como rama de la semiótica, nos permite adentrarnos en la semiótica de la cultura, para la cual el comportamiento humano es una forma de comunicación, ya que en situaciones codificadas permite situar y determinar la actuación de un individuo en relación con otros (Courtés, 1997). Este mismo autor considera que hay tres niveles dentro de la semiótica visual: 1) nivel pre-iconográfico, 2) nivel iconográfico y 3 ) nivel iconológico.

El nivel iconológico, escogido para este estudio, consiste en ahondar sobre el concepto o las ideas que se esconden en los asuntos o temas figurados, y sobre su alcance en un contexto cultural determinado (Courtés, 1997). De acerdo a Panofsky, la iconología "resalta la interpretación del significado intrínseco" de la imagen (2005: 124). Siguiendo este método, en cada una de las publicaciones, se identificarán tres aspectos a nivel iconológico, usando las categorías propuestas por Rodríguez (2017): 1) Contexto social, 2) Cultura e 3) Identidad. 


\subsection{Muestra y plantilla de estudio}

Este estudio utilizará el perfil de Instagram de la cantante Rosalía (@rosalia.vt). La unidad de análisis comprende todas aquellas publicaciones subidas a partir del 1 de enero de 2018 hasta el 31 de julio de 2020. El corpus incorpora 449 publicaciones. Se ha escogido este periodo de tiempo debido a que se considera que la artista dio el salto internacional a partir del lanzamiento del álbum El Mal Querer el 2 de noviembre de 2018.

Para responder al objetivo 1 y determinar cómo aprovecha Rosalía las potencialidades de la red social Instagram, se analizarán cuatro variables: A. Tipo de publicación, B. Formato de pie de foto, C. Aparición o no de etiquetas y menciones y D. Categorías. Cada una de estas variables consta de diferentes subcategorías, como puede verse en la tabla 1.

Tabla 1. Ficha de análisis del perfil de Instagram de Rosalía

\begin{tabular}{|l|l|}
\hline \multirow{4}{*}{ Tipo de publicación } & $\begin{array}{l}\text { A1. Imagen } \\
\text { A2. Más de una imagen o vídeo } \\
\text { F3. Vídeo }\end{array}$ \\
\hline \multirow{5}{*}{ Formato de pie de foto } & $\begin{array}{l}\text { B1. Texto } \\
\text { B2. Emojis } \\
\text { B3. Texto y emojis } \\
\text { B4. Sin pie de foto }\end{array}$ \\
\hline Etiquetas y menciones & \\
\hline \multirow{5}{*}{ Categorías } & D1. Selfies \\
& D2. Amigos u otras celebrities \\
& D3. Conciertos, backstage y premios \\
& D4. Promoción de productos \\
& D5. Moda, marcas y estilismos \\
& D6. Promoción de videoclips \\
& D7. Activismo y colaboraciones con entidades sociales \\
\hline
\end{tabular}

Fuente: Elaboración propia.

Para realizar el análisis cualitativo de contenido $(\mathrm{O} 2)$, se ha tomado la propuesta de Rodríguez (2017) como base para examinar las publicaciones desde un punto de vista iconológico (tabla 2):

Tabla 2. Análisis semiótico-iconológico de las publicaciones

\begin{tabular}{|l|l|}
\hline Contexto social & $\begin{array}{l}\text { Describe el espacio o entorno que puede ser físico o simbólico } \\
\text { que sirve de marco para mencionar o entender un episodio. }\end{array}$ \\
\hline Cultura & $\begin{array}{l}\text { Conjunto de conocimientos, ideas, tradiciones y costumbres } \\
\text { que caracterizan a un grupo social. }\end{array}$ \\
\hline Identidad & $\begin{array}{l}\text { Conjunto de rasgos o características de una persona o cosa } \\
\text { que permitan distinguirla de otras en un conjunto. }\end{array}$ \\
\hline
\end{tabular}

Fuente: Elaboración propia a partir de Rodríguez (2017).

La plantilla de análisis de contenido se ha elaborado a partir del modelo propuesto por $\mathrm{Hu}$, Manikonda \& Kambhamapati (2014), basada en 8 categorías de codificación: 1) selfies, 2) amigos, 3) actividad exterior e interior, 4) comida, 5) gadgets y vehículos, 6) moda, 7) mascotas, 8) fotos con texto. No obstante, al realizar un primer análisis de la muestra, se ha identificado la existencia de otras variables y se ha modificado la plantilla original de análisis, de manera que ésta se adapte al presente estudio y recoja todas las variables a tener en cuenta. Las categorías analizadas se recogen en la tabla 3. 
Tabla 3. Categorías de análisis del perfil de Instagram de Rosalía

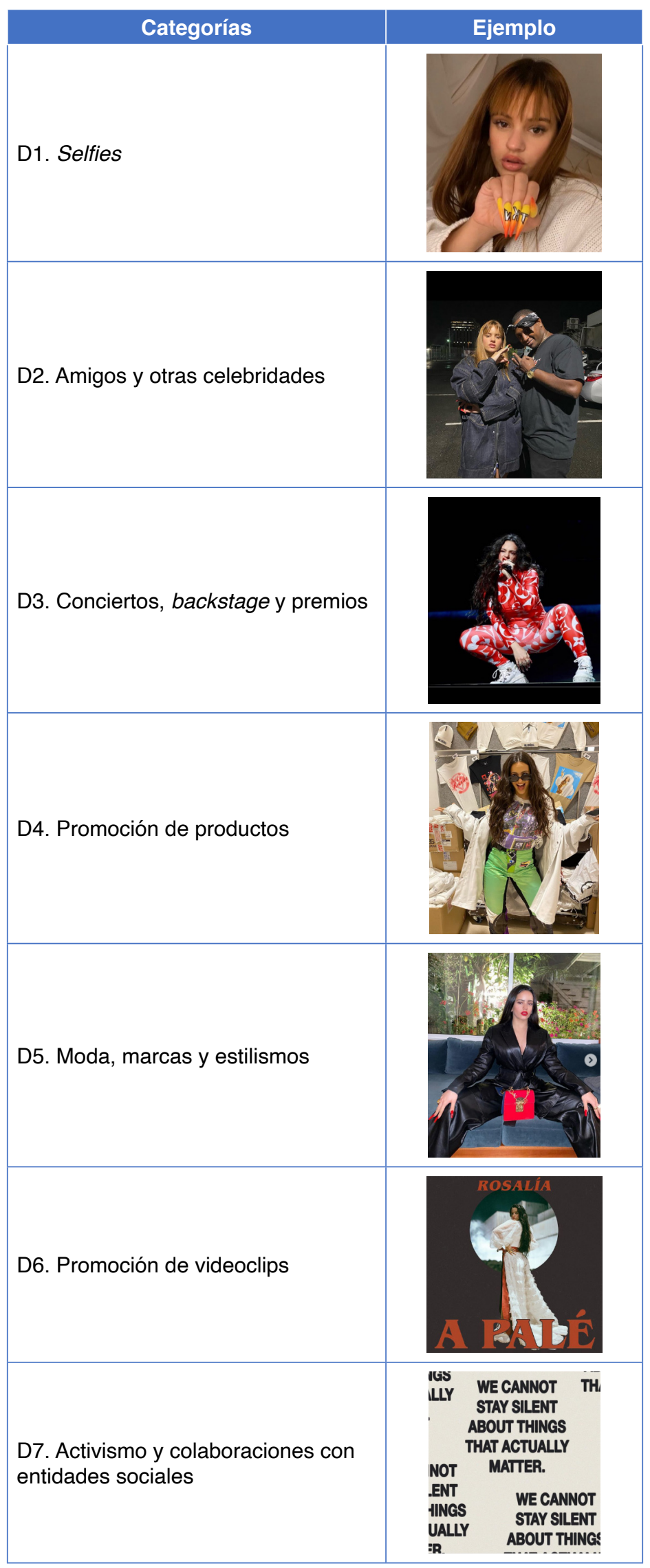

Fuente: Elaboración propia a partir de Hu, Manikonda \& Kambhamapati, 2014. 


\section{Resultados}

\subsection{Análisis estadístico descriptivo}

Como resultado de las fechas elegidas para el análisis (1 de enero de 2018 hasta el 31 de julio de 2020), se han recogido 449 publicaciones en total. De ellas, 223 corresponden a una sola imagen (49,7\%), 125 a una publicación con más de una imagen o vídeo $(27,8 \%)$ y 101 son vídeos $(22,5 \%)$.

En cuanto a los pies de foto, encontramos en el gráfico 1 un mayor porcentaje $(66,8 \%)$ de publicaciones con pies de foto que mezclan texto y emojis, un $23,2 \%$ de publicaciones solo tienen como pie de foto un emoji o una combinación de emojis, un 5,3\% son de solo texto y, finalmente, un 4,7\% de publicaciones que no tienen ningún pie de foto.

Gráfico 1. Porcentajes de pies de foto

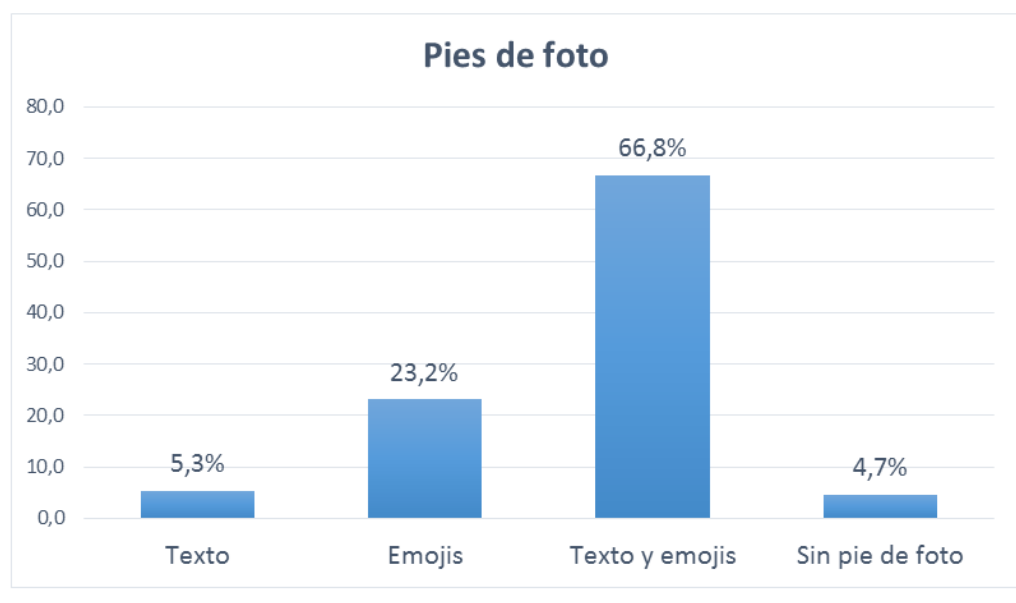

Fuente: Elaboración propia.

$\mathrm{Al}$ analizar el porcentaje de etiquetas y menciones utilizadas en las publicaciones, se puede observar en el gráfico 2 que Rosalía hace uso de esta affordance en el 66,1\% de las publicaciones analizadas:

Gráfico 2. Porcentaje de etiquetas y menciones

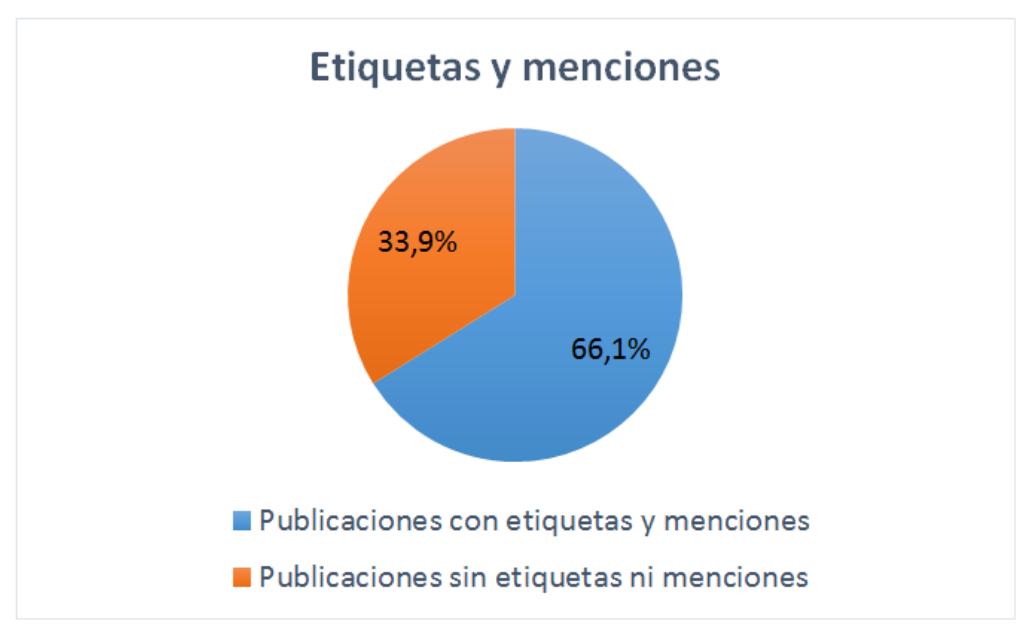

Fuente: Elaboración propia. 
En cuanto a las categorías analizadas (gráfico 3), que no son excluyentes, en el conjunto del total de publicaciones la que tiene más presencia en el perfil de Rosalía es la D5. Moda, marcas y estilismos (38\%). La segunda categoría con más presencia en el feed de la cantante es la D3. Conciertos, bac$k s t a g e$ y premios (21\%). Y la tercera es la D2. Amigos y otras celebridades (17\%).

Gráfico 3. Porcentajes de cada categoría de análisis

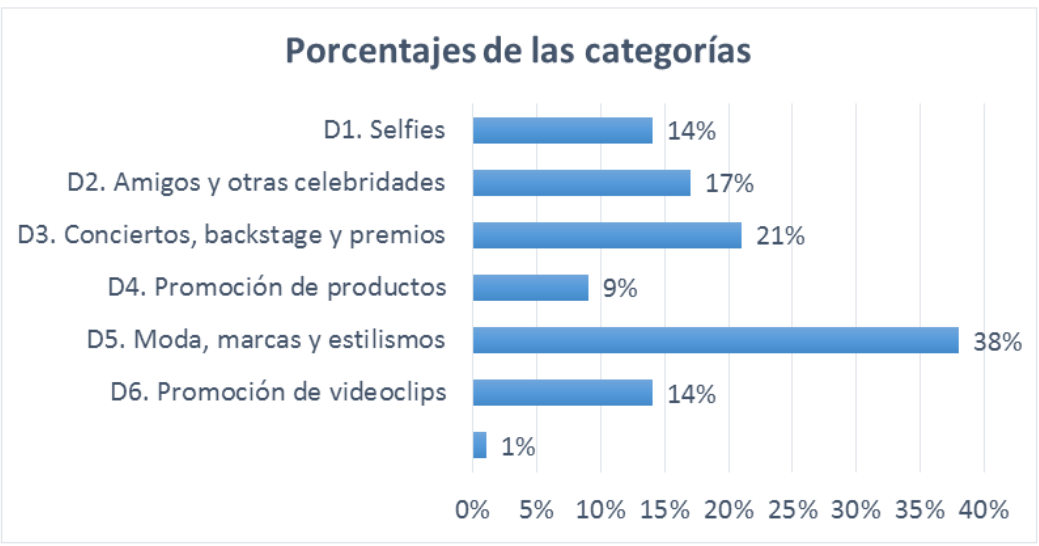

Fuente: Elaboración propia.

Las imágenes y vídeos en los que Rosalía promociona sus videoclips conforman el 14\% de las publicaciones, siendo el mismo porcentaje que el de los selfies. Sin embargo, se observa un porcentaje mucho menor de las categorías D4. Promoción de productos y D7. Activismo y colaboraciones con entidades sociales, con un $9 \%$ y $1 \%$ de presencia en el análisis, respectivamente.

Si atendemos al porcentaje de cada tipo de publicación en las tres categorías más recurrentes, encontramos que en la categoría D5. Moda, marcas y estilismos (gráfico 5), la imagen es el formato más recurrente (59,3\%), seguido de la publicación de varias imágenes o vídeos $(31 \%)$, mientras que el vídeo aparece en un $8,7 \%$ de las veces.

Gráfico 4. Porcentaje de cada tipo de publicación por las tres categorías más recurrentes

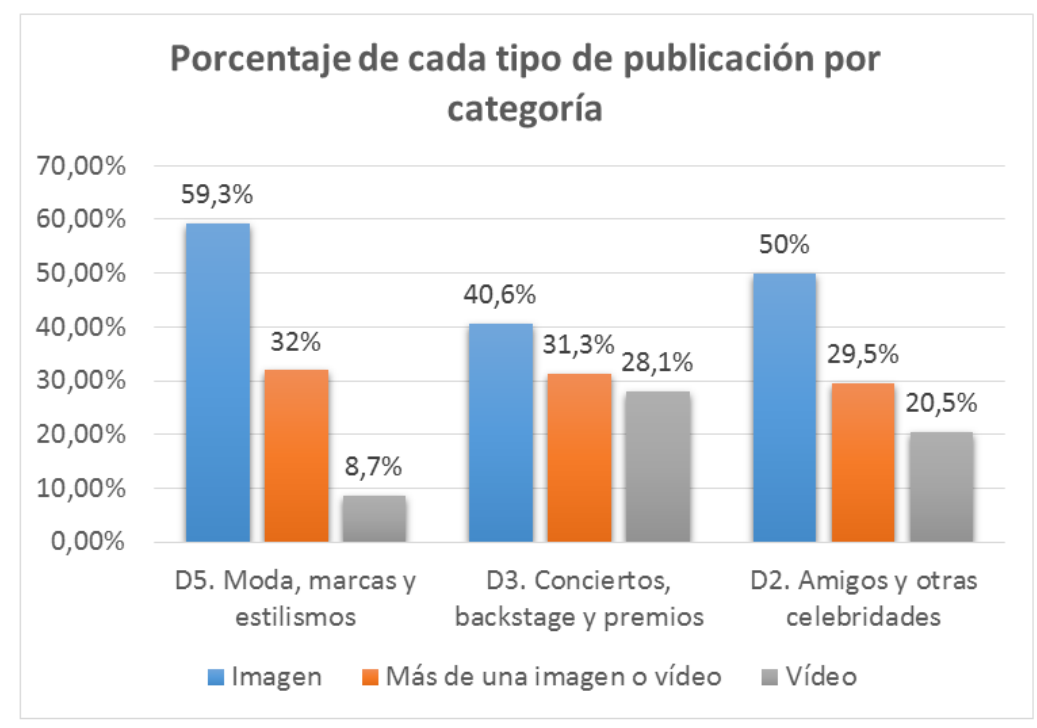

Fuente: Elaboración propia. 
Se repite el mismo patrón en la categoría D3. Conciertos, backstage y premios, ya que la imagen vuelve a ser el tipo de publicación más recurrido, en un 40,6\% de las veces, la combinación de imágenes y vídeos en un $31,3 \%$, y los vídeos en último lugar, con un $28,1 \%$. No obstante, el formato vídeo toma mayor relevancia en esta categoría, igualándose con el porcentaje de las publicaciones con más de una imagen o vídeo.

En el caso de la categoría D2. Amigos y otras celebridades, la mitad de los posts son imágenes (50\%), el 20\% son vídeos y el 29,5\% pertenecen a las publicaciones con más de una imagen o vídeo.

En el gráfico 5 se reflejan los porcentajes de la utilización de cada formato. Como se ha comentado, la imagen es el tipo de publicación que predomina en todas las categorías, menos en la D6. Promoción de videoclips, donde el vídeo es el formato más utilizado (46,8\%), seguido por la imagen $(43,5 \%)$ y la publicación de varias imágenes o vídeos $(9,7 \%)$. Esta inversión del patrón anterior se puede explicar por la naturaleza audiovisual de la temática de los videoclips.

Tanto en las categorías D2. Amigos y otras celebrities, como en la D4. Promoción de productos, Rosalía publica imágenes de forma usual, seguida por la publicación de varias imágenes o vídeos y, por último, vídeos. Sin embargo, en el caso de los selfies, la artista publica mayor cantidad de vídeos en comparación con los publicados en otras categorías $(35,5 \%) \mathrm{y}$, en menor medida, varias imágenes o vídeos $(16,1 \%)$.

Gráfico 5. Porcentaje de cada tipo de publicación en cada categoría

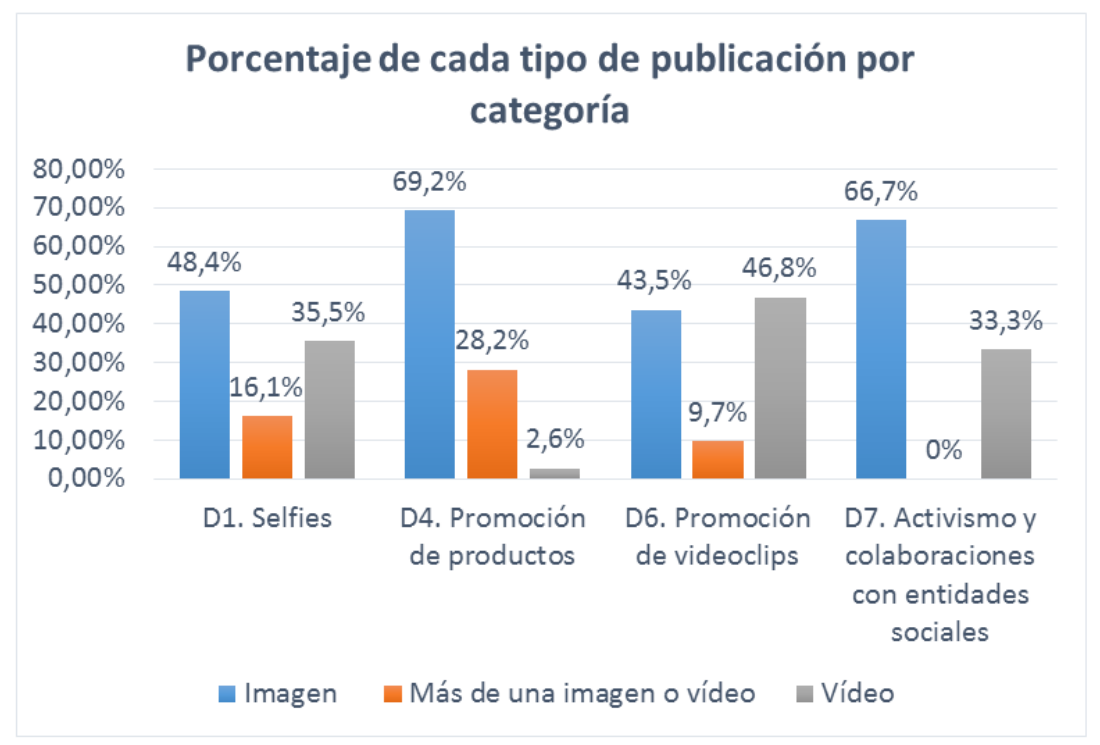

Fuente: Elaboración propia.

Por último, en las publicaciones relacionadas con activismo o colaboraciones con entidades sociales, Rosalía hace uso de la imagen como principal recurso $(66,7 \%)$ y de los vídeos en el 33,3\% de los casos.

\subsection{Análisis cualitativo de contenido}

El estudio de análisis de contenido parte de la evaluación de las tres categorías con más presencia en el perfil de Instagram de Rosalía: D5. Moda, marcas y estilismos, D3. Conciertos, backstage y premios y D2. Amigos y otras celebridades. De estas tres variables seleccionadas, se ha calculado 
el engagement, definido como "un estado mental subjetivo que supone una atención enfocada en un objeto (...) que se manifiesta en diversas representaciones simbólicas (principalmente, "me gusta", Compartir y Comentar), que pueden ser registradas y clasificadas para su medición y estudio" (Ballesteros-Herencia, 2019, p. 216).

En este estudio se ha utilizado la fórmula propuesta por Metricool para calcular el grado de interés e interacción de los seguidores de Rosalía. Metricool es una herramienta de analítica para analizar y medir contenidos digitales. Entre sus funciones, proponen calcular el engagement a través de una fórmula que tiene en cuenta el uso de las affordandes de las redes sociales por parte de los seguidores de una determinada cuenta, en proporción al alcance de la red del usuario analizado. Siguiendo dicha fórmula (imagen 1), para esta investigación se han sumado los "me gusta" y los comentarios de cada post de la muestra, divididos entre los seguidores de Rosalía. El resultado se ha multiplicado por 1.000 .

Imagen 1. Fórmula de cálculo de engagement en Instagram

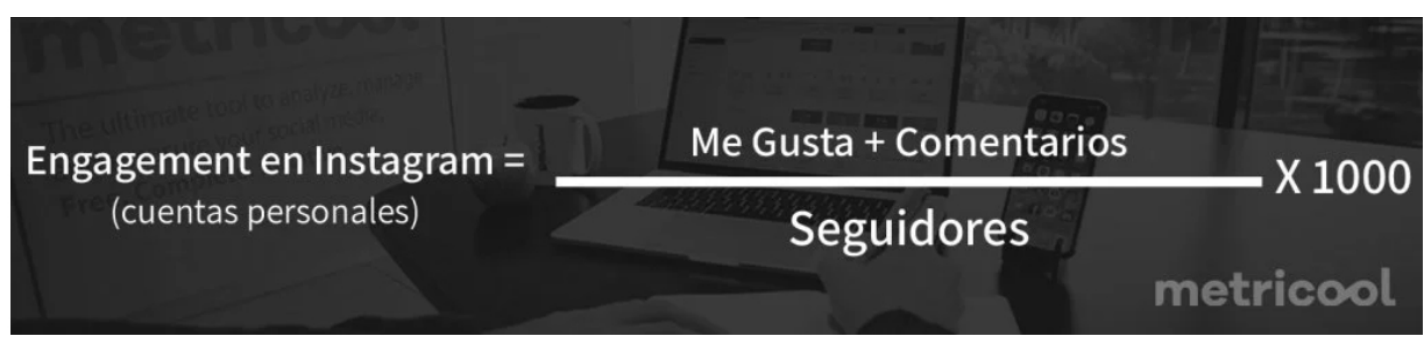

Fuente: Montells, L. (2018)

Se hará una descripción general de las cinco fotografías con más engagement de estas tres categorías, para tener una muestra representativa de las publicaciones que más éxito han tenido entre los seguidores de Rosalía en Instagram. La descripción se realizará de forma general en cada fotografía, a partir del análisis iconológico propuesto por Rodríguez (2017): 1) Contexto social, 2) Cultura y 3) Identidad. De esta manera, podremos ahondar sobre los conceptos e ideas que se esconden en el contexto cultural determinado de cada imagen y vídeo que publica la artista catalana.

\subsubsection{Moda, marcas y estilismos}

La tabla 4 muestra las tres publicaciones de la categoría D5. Moda, marcas y estilismos con mayor engagement en el perfil de Rosalía.

Tabla 4. Variables de la evaluación del engagement en la categoría D5. Moda, marcas y estilismos

\begin{tabular}{|c|c|c|c|c|}
\hline Fecha & Me gusta & Comentarios & Seguidores & Engagement \\
\hline $16 / 02 / 20$ & 2.874 .225 & 23.779 & 12,3 millones & 235,61 \\
\hline $02 / 05 / 20$ & 2.851 .375 & 23.436 & 12,3 millones & 233,72 \\
\hline $05 / 07 / 20$ & 2.157 .947 & 10.526 & 12,3 millones & 176,29 \\
\hline
\end{tabular}

Fuente: Elaboración propia.

La primera publicación con mayor engagement data del 16 de febrero de 2020, con 2.874.225 "me gusta", 23.779 comentarios y un engagement de 235,61. La publicación consta de cinco imágenes. La cantante no especifica la ubicación ni el contexto en el que están tomadas las fotografías. Tampoco hay personas etiquetadas ni mencionadas (Imagen 2). 
Imagen 2. 16/02/20, categoría D5

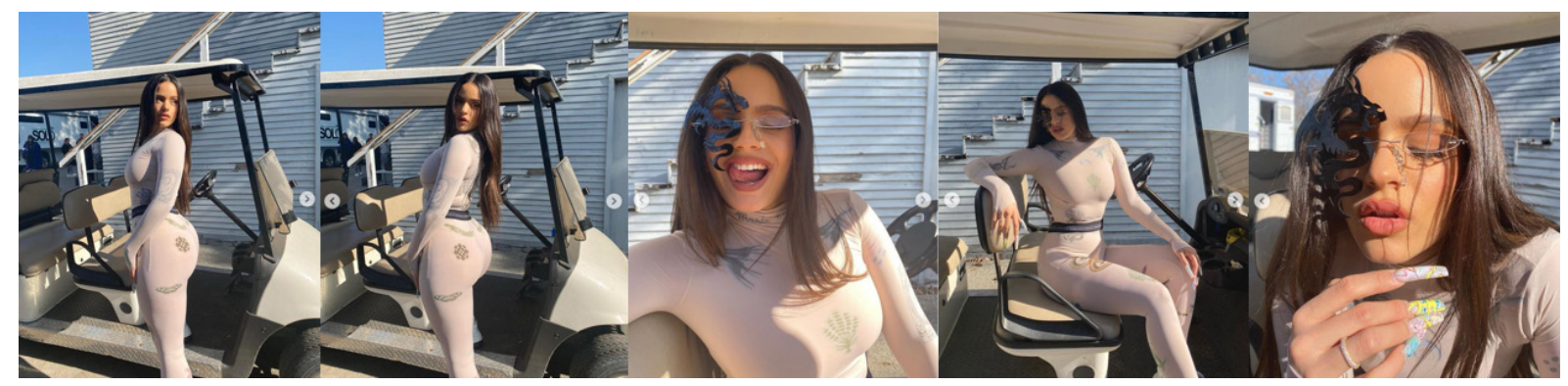

Fuente: Instagram.

Tres de las imágenes que componen la publicación muestran a Rosalía en un plano entero, llevando un mono blanco semitransparente y con estampado. Las dos fotos restantes muestran a Rosalía en primer plano, portando unas gafas de cristal transparente y con un detalle de dragón negro. En una de ellas, aparecen también sus manos y sus uñas acrílicas extra largas, decoradas con dibujos estilo anime. Rosalía habla de sus uñas como "unas obras de arte en miniatura" que se han vuelto una de sus marcas de identidad (El País, 2020) y que aparece de forma continuada en sus fotos de Instagram, así como en sus videoclips y looks en los escenarios.

Rosalía acompaña la publicación con un pie de foto en el que solo aparecen emojis de cerezas, que podrían interpretarse como un símbolo que se asemeja a la anatomía de su cuerpo. Este post tuvo muchas reacciones en diferentes medios, donde relacionaban el estilo de las fotografías y las poses al estilo de la familia Kardashian (Gamboa, 2020).

Imagen 3. 02/05/20, categoría D5

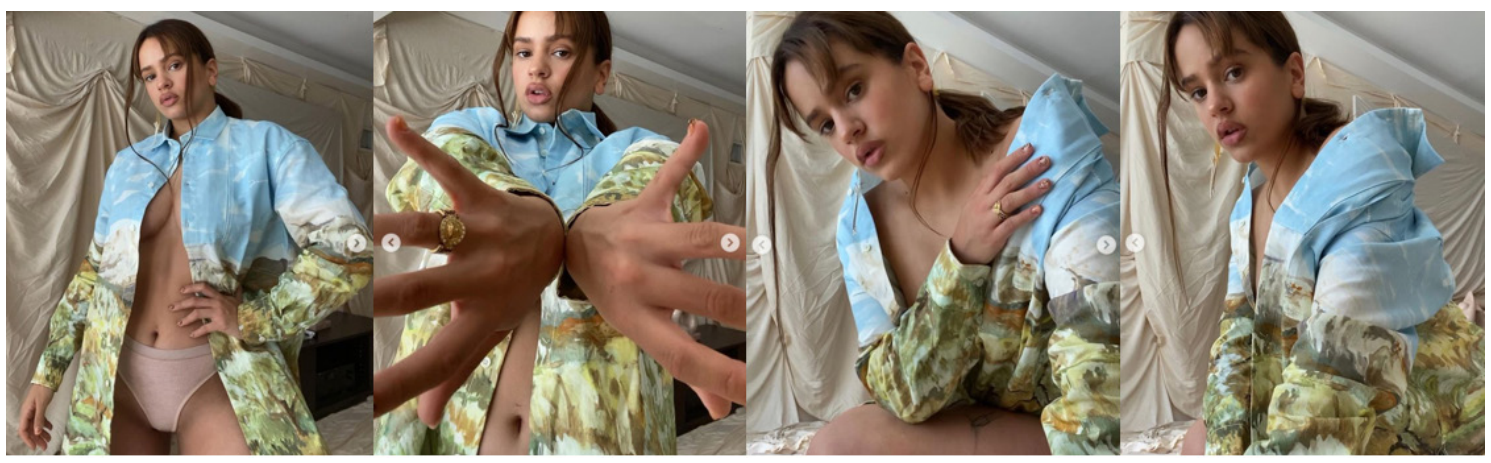

Fuente: Instagram.

La segunda publicación con más engagement dentro de la categoría D5. Moda, marcas y estilismos, data del 2 de mayo de 2020 (Imagen 3). Con más de dos millones y medio de likes y más de 23.000 comentarios, Rosalía se presenta ante sus seguidores en una localización de interior. En el momento de subida de las fotografías, la cantante estaba confinada en Miami, por lo que las fotos se hicieron desde esa localidad.

Rosalía publicó cuatro fotos en una misma publicación, vistiendo las mismas prendas. En todas ellas aparece con semblante serio y sugerente, pero la segunda destaca por el gesto característico de las manos, al estilo de los bailaores de flamenco y la cultura gitana, en las que porta un anillo dorado. Este es uno de los gestos más vistos en las actuaciones y videoclips de Rosalía, y que al principio fueron objeto de crítica y acusación por cometer apropiación cultural. Sin embargo, Rosalía ha afirmado que 
no le afectan este tipo de críticas: "Es bonito y enriquecedor que, en un mundo globalizado, nos involucremos en muchas culturas diferentes y no solo en la que hay a nuestro alrededor" (Chocano, 2020). Esta vez, las uñas están pintadas con motivos geométricos y sin la longitud habitual.

La artista catalana aparece vestida solo con una prenda, firmada por el diseñador francés Simon Porte Jacquemus. Según el diseñador indica en su propio perfil de Instagram, su creación está inspirada en los campos de la Provenza y en las obras de arte de Cézanne. Aunque Rosalía no menciona ni etiqueta la marca de la prenda, los medios de comunicación especializados en moda analizaron esta publicación, destacando tanto la camisa y su diseñador (Martíns, 2020b) como el posado provocativo de las fotografías (Antena 3 Noticias, 2020).

Imagen 4. 05/07/20, categoría D5

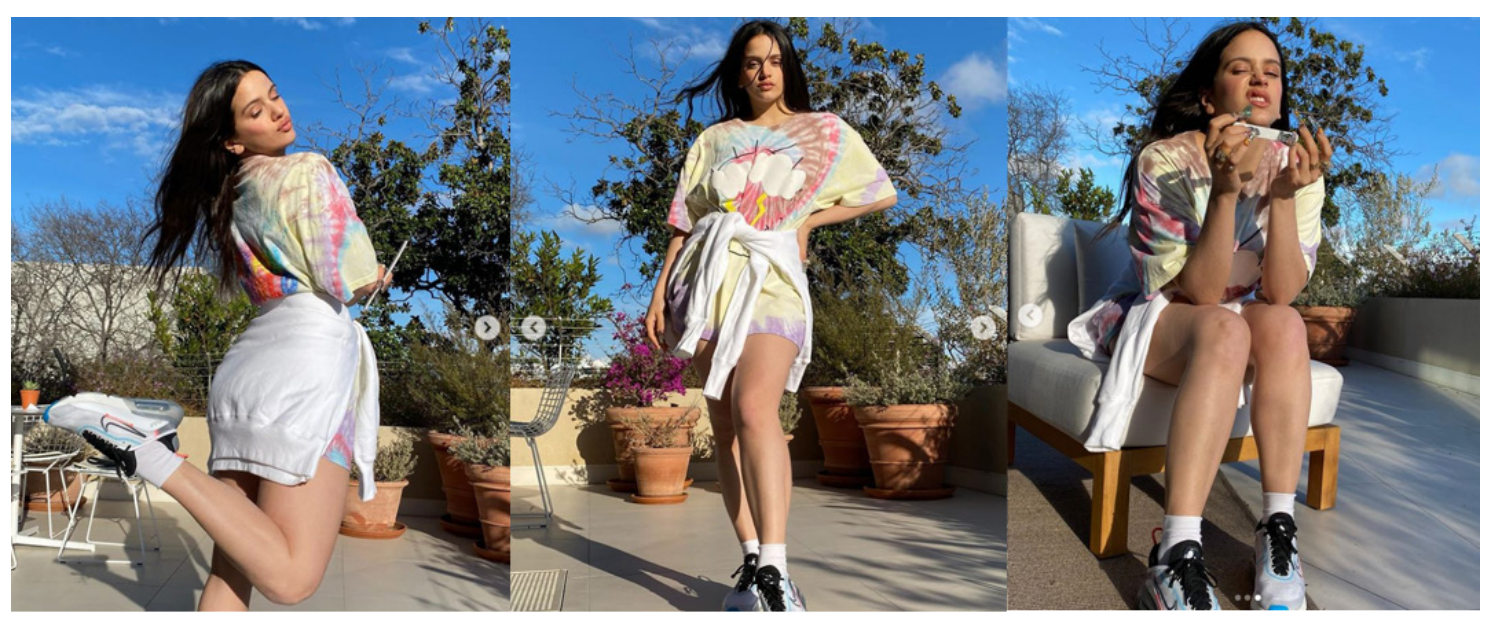

Fuente: Instagram.

La figura 4 nos muestra la tercera publicación de Rosalía con más engagement, con más de dos millones y medio de visitas y de 10.000 comentarios. El post data del 5 de julio de 2020 y cuenta con tres imágenes. En todas ellas, la localización es la misma: una terraza exterior. El pie de foto cuenta solo con emojis de soles.

Las imágenes muestran a Rosalía de cuerpo entero, pero con una actitud diferente en las tres fotografías. La primera es una actitud divertida, risueña, mientras que la segunda y la tercera da una imagen más agresiva, mirando directamente a la cámara. En la última foto aparece limándose las uñas y mostrando unas uñas largas con relieves y las manos decoradas con anillos grandes.

En cuanto a la indumentaria, presenta un look casual: una camiseta larga, una sudadera anudada a la cintura y unas deportivas Nike, cuya marca se ve claramente en todas las fotografías, aunque no la mencione ni la etiquete. Unos días más tarde, el 8 de julio de 2020, la cantante posteaba un vídeo en su Instagram en el que anunciaba su relación comercial con Nike y se convertía en la embajadora de las nuevas Nike Air Max 2090, unos zapatos deportivos de inspiración futurista y vanguardista (Muñoz, 2020), que la firma ha catalogado dentro de su colección "Nuevos iconos" (El Corte Inglés, 2020). En el vídeo promocional, Rosalía narra: "El futuro no es algo que esperas. Es algo que haces".

\subsubsection{Conciertos, backstage y premios}

Pasamos a continuación a examinar las publicaciones de la categoría D3. Conciertos, backstage y premios, que como hemos visto en el análisis estadístico es la segunda más frecuente en el perfil de Rosalía, con un $21 \%$ de presencia. La tabla 5 muestra las variables de evaluación de engagement de la categoría mencionada. 
Tabla 5. Variables de la evaluación del engagement en la categoría D3. Conciertos, backstage y premios

\begin{tabular}{|c|c|c|c|c|}
\hline Fecha & Me gusta & Comentarios & Seguidores & Engagement \\
\hline $27 / 01 / 20$ & 1.868 .369 & 12.356 & 12,3 millones & 152,90 \\
\hline $13 / 01 / 20$ & 1.420 .720 & 5.215 & 12,3 millones & 115,92 \\
\hline $13 / 12 / 19$ & 1.406 .289 & 8.233 & 12,3 millones & 115,00 \\
\hline
\end{tabular}

Fuente: Elaboración propia.

La siguiente imagen se publicó en el perfil de Rosalía el 27 de enero de 2020, y se trata de la foto con más engagement $(152,90)$ dentro de la categoría D3. Conciertos, backstage y premios (Imagen 5). La foto tiene 1.868.369 "me gusta" y 12.356 comentarios. Fue tomada en los Premios Grammy 2020, celebrados en Los Ángeles, EEUU. En la gala, Rosalía se llevó el premio a Mejor disco latino de rock, urbano o alternativo por su álbum El Mal Querer.

Imagen 5. 27/01/20, categoría D3

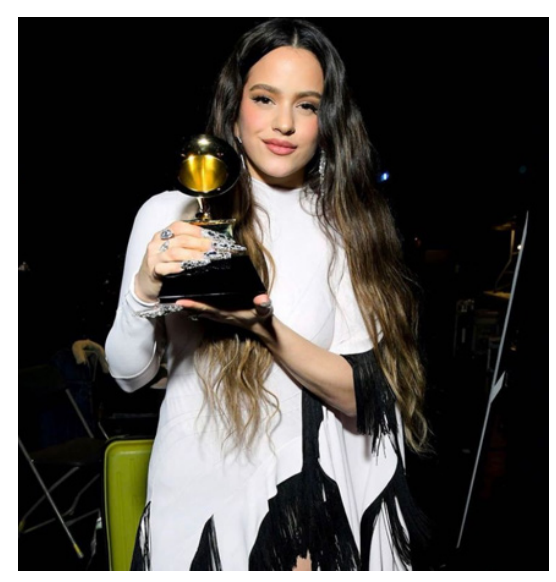

Fuente: Instagram.

En el pie de foto, Rosalía expresa su sorpresa al recibir el premio, y menciona a la Academia que concede los grammys en forma de agradecimiento. En la imagen, posa con el gramófono dorado que le concedieron en la gala. Resaltan las uñas acrílicas, decoradas con un estampado a juego con el vestido, firmado por el diseñador francés Thierry Mugler. El vestido es de inspiración flamenca, especialmente diseñado para Rosalía, con volantes, flecos y mangas asimétricas que se asemejan a una mantilla.

Imagen 6. 13/01/20, categoría D3

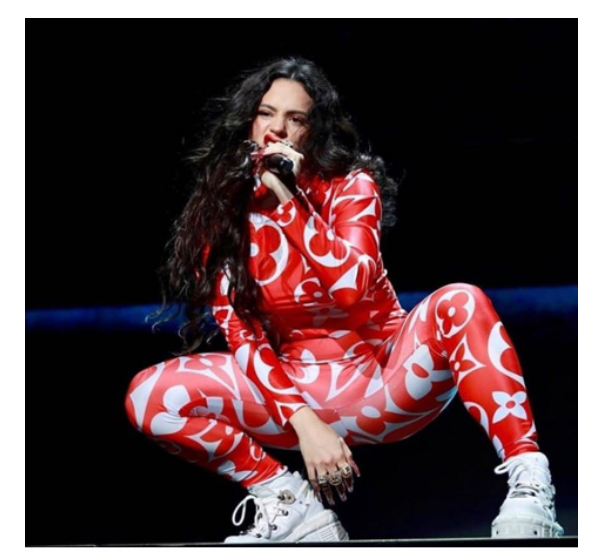

Fuente: Instagram. 
La segunda publicación con mayor engagement dentro de la categoría D3 data del 13 de enero de 2020 , cuenta con casi un millón y medio de likes, más de 5.000 comentarios y un engagement de 115,92. La publicación consta de una sola imagen (Figura 6). En el pie de foto tan solo aparece un emoji de un diablo rojo, a conjunto con el color de la ropa que lleva en la imagen y que puede representar también la actitud que presenta en el escenario.

Rosalía se encuentra sobre el escenario, durante un concierto que ofreció en Los Ángeles. La postura que tiene es de cuclillas, una pose sobre la que se ha hablado como "viral" entre los influencers de Instagram (Pérez, 2017), también llamada squatting pose, que suele ser fotografiada en un ángulo contrapicado y está relacionado con la música y los inicios de la cultura hip-hop.

El body ajustado que lleva es una creación del joven diseñador estadounidense Imran Moosvi (Imran Potato en Instagram), seguidor de la tendencia bootleg, que consiste en crear versiones no autorizadas de las marcas de lujo (Nigramercato, 2019) y que se han puesto de moda entre las celebridades en el mundo de la música. Según Pablo López, estilista y fundador de la marca Sisyphe, la tendencia de la "logomanía" está vinculada con los deseos de aspiración y reafirmación, como una manera rápida de presumir del éxito y la fama, aunque la indumentaria no sea de una marca original: "Si Rosalía lleva un chándal la gente no se para a analizar si es una versión o un original. Por tanto, creo que es una buena estrategia de marketing para la firma, sea o no suya la prenda" (Ferrero, 2019). También lleva unas zapatillas deportivas blancas que completan su atuendo al estilo athleisure, una tendencia que adapta la ropa deportiva a las prendas más casuales (Personalitia, 2019). Esta forma de vestir se observa de forma repetida en el Instagram de Rosalía, pero también en sus videoclips, en especial en su sencillo debut Malamente.

Imagen 7. 13/12/19, categoría D3

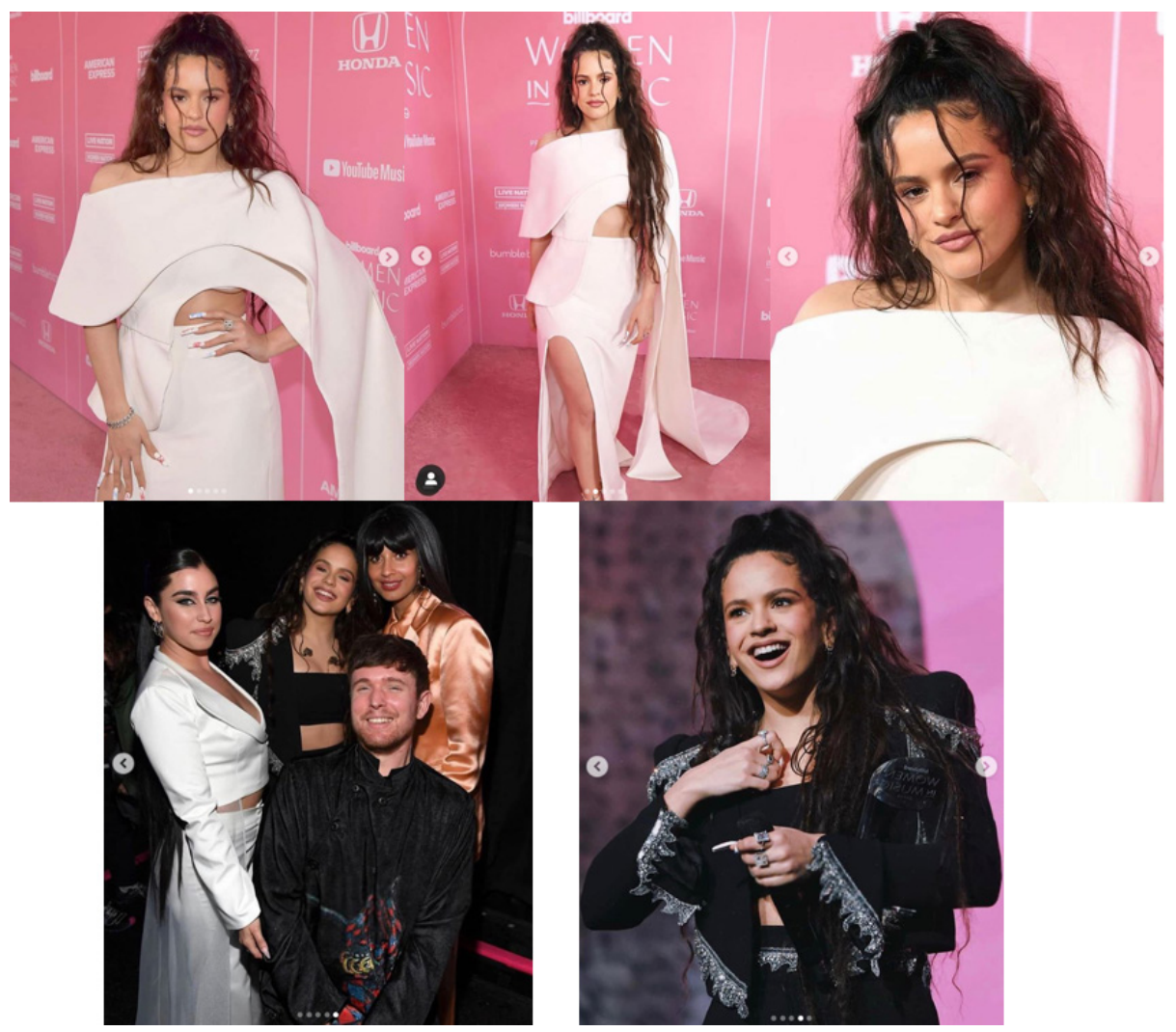

Fuente: Instagram. 
El 13 de diciembre de 2019, Rosalía publicó en su perfil de Instagram las fotografías de los Premios Billboard Women in Music 2019, celebrados en Los Ángeles (Imagen 7). La cantante ganó el premio Rising Star, como artista emergente del año. La publicación cuenta con 1.406.289 millones de likes y 8.233 comentarios, por lo que es la tercera foto con más engagement de esta categoría.

La publicación tiene cinco fotografías, tres de ellas de Rosalía posando en el photocall, y las dos siguientes ya en la gala. En el pie de foto, la cantante solo menciona a la cuenta de los premios Billboard junto a emoticonos de corazones, especificando la ubicación del evento. En las tres primeras fotografías, Rosalía posa con un vestido de diseño asimétrico de color blanco, firmado por el diseñador italiano Antonio Grimaldi. En las uñas aparecen términos en japonés y en español. Entre ellas, la palabra 'querer', en referencia a su álbum El Mal Querer. En la cuarta foto, sale con otras tres celebridades: la cantante Lauren Jauregui, el cantante James Blake y la actriz Jameela Jamil; mientras que en la última imagen aparece sonriente sobre el escenario.

\subsubsection{Amigos y otras celebridades}

Finalmente, examinamos a continuación la tercera categoría, D2. Amigos y otras celebridades, cuyo porcentaje de presencia era del 17\% en el análisis estadístico. La tabla 6 muestra las variables de evaluación de engagement de esta categoría.

Tabla 6. Variables de la evaluación del engagement en la categoría D2. Conciertos, backstage y premios

\begin{tabular}{|l|l|l|l|l|}
\hline Fecha & Me gusta & Comentarios & Seguidores & Engagement \\
\hline $12 / 01 / 20$ & 2.689 .135 & 18.498 & 12,3 millones & 220,13 \\
\hline $15 / 12 / 19$ & 2.489 .720 & 24.685 & 12,3 millones & 204,42 \\
\hline $18 / 12 / 19$ & 1.523 .233 & 11.241 & 12,3 millones & 124,75 \\
\hline
\end{tabular}

Fuente: Elaboración propia.

La imagen 8 muestra la primera de las publicaciones que se van a analizar de la categoría D2. Amigos y otras celebridades. En ella, Rosalía aparece acompañada de Kylie Jenner, la hermana pequeña de la familia de celebridades Kardashian. La foto ha obtenido más de dos millones y medio de likes y 18.498 comentarios, con un engagement de 220,13.

Imagen 8. 12/01/20, categoría D2

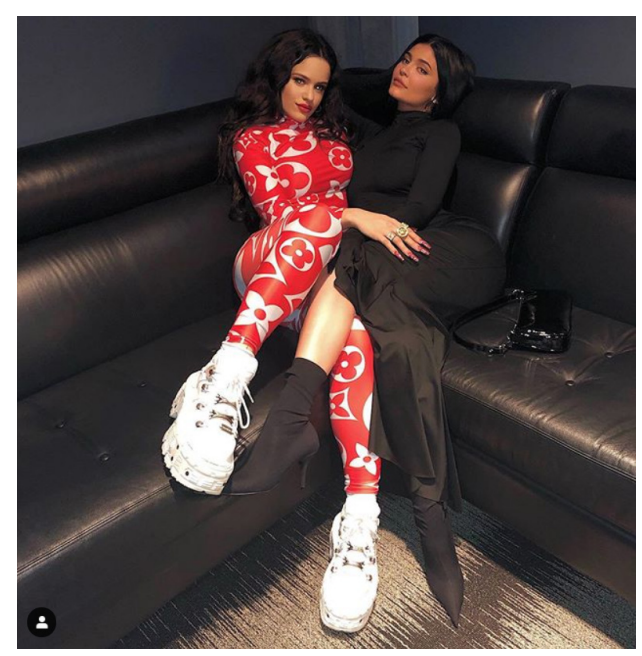

Fuente: Instagram. 
La foto se hizo en el backstage del concierto que dio Rosalía en el Staples Center de Los Ángeles. Esta es la segunda imagen que publicaron posando juntas, y en el pie de foto, Rosalía indica: "I said yes" (He dicho sí), acompañada de un anillo de compromiso. Kylie Jenner publicó la misma fotografía en su perfil de Instagram el mismo día, poniendo el emoji de un anillo en el pie de foto. Muchos de los seguidores de ambas entendieron las publicaciones como una seña de su nueva amistad, que fue comentada también en revistas como Vogue (Lázaro, 2020) o Harper's Bazaar (Martíns, 2020a).

Rosalía lleva un mono rojo ajustado del diseñador Imran Moosvi con el Logo de Louis Vuitton a modo de estampado. Como se ha comentado anteriormente, forma parte del bootleg, la tendencia de la "logomanía". Esta tendencia se incluye a su vez dentro de la moda ratchet, que "surge de una jerga utilizada como sinónimo de trashy, urbano, burdo, ghetto y el término hace referencia a algo que es desagradable, sucio o un insulto. Este estilo es caracterizado por el exceso, las prendas holgadas, los conjuntos de dos piezas, los crop tops, las joyas, como en la época del bling bling del hip hop, las dentaduras grillz y los logos expuestos en el exterior de las prendas" (Uria, 2019). De acuerdo a esta autora, la moda ratchet está ganando popularidad gracias al avance de las redes sociales y la influencia de artistas procedentes de la música popular actual, quienes convierten este estilo de vestir en una de sus características personales, ligando la moda a su identidad artística, como se observa en el caso de Rosalía.

Imagen 9. 15/12/19, categoría D2

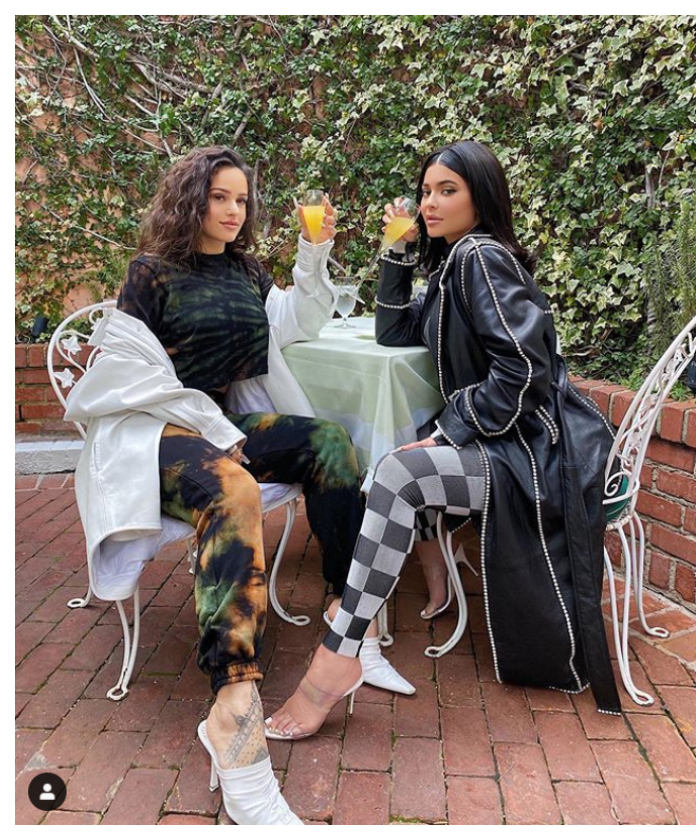

Fuente: Instagram.

El 15 de diciembre de 2019, Rosalía publicó en su instagram la primera fotografía con Kylie Jenner. Dentro de la categoría D2. Amigos y otras celebrities, vuelve a ser la pequeña del clan Kardashian la acompañante de Rosalía en las publicaciones con más engagement (Imagen 9). La foto tiene 2.489.720 "me gusta" y 24.685 comentarios. La cantante acompaña la foto con un pie de foto con emojis de unos corazones y copas.

Las dos celebridades aparecen tomando cócteles en una terraza. Aunque las dos llevan zapatos con tacón, Rosalía viste ropa deportiva con estampado desteñido de color verde, negro y naranja. Por encima, una chaqueta blanca a juego con los zapatos, que resaltan al estar en primer plano, donde 
se aprecia el tatuaje que tiene en el empeine, con el estilo de los diseños hindúes que se utilizan en los tatuajes de henna.

La amistad de Rosalía con Kylie Jenner ha concitado la atención de los medios de comunicación, ya que actualmente las Kardashian son la familia más mediática a nivel mundial. Esta relación permite a Rosalía darse a conocer a otros públicos, así como mejorar relaciones con otros cantantes.

Imagen 10. 18/12/19, categoría D2

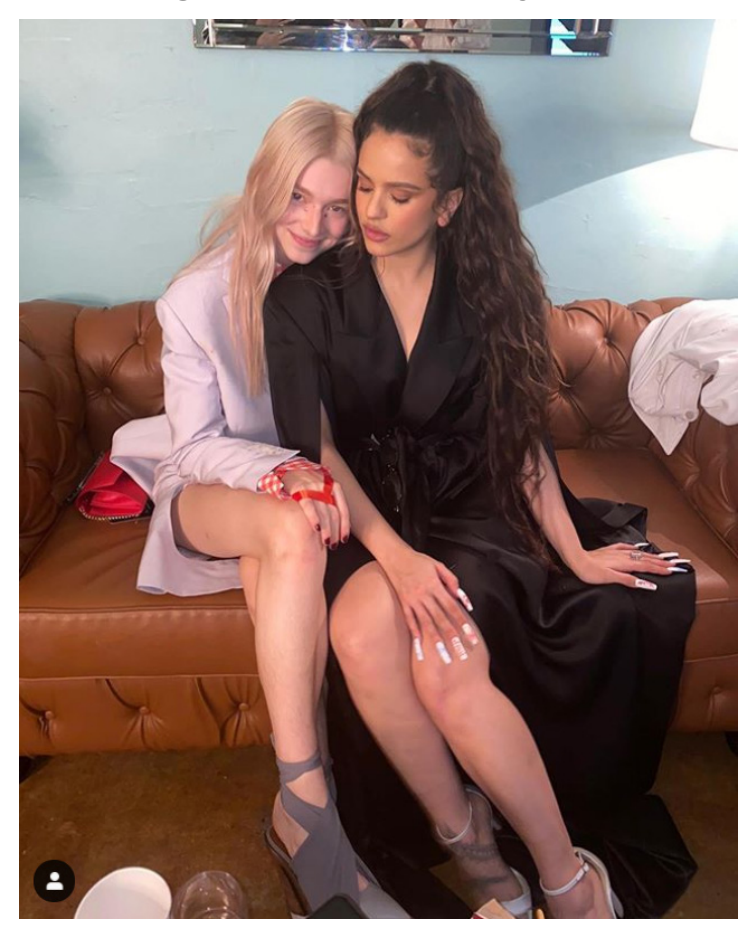

Fuente: Instagram.

La imagen 10 muestra la tercera de las publicaciones con más engagement dentro de la categoría D2. Amigos y otras celebridades. La fotografía tiene 1.523.233 likes y 11.241 comentarios. Se publicó el día 18 de diciembre de 2019, pero Rosalía no especifica ubicación. Acompaña la foto con un emoticono de un corazón.

En la foto, aparecen Rosalía y la actriz estadounidense Hunter Schafer, protagonista junto a Zendaya en la serie de HBO Euphoria, que retrata la vida de un grupo de adolescentes en torno a temas como las adicciones, la soledad y la confusión de una generación marcada por Internet. La foto parece realizada en los camerinos de los Billboard Women in Music 2019, celebrado en Los Ángeles. En ellos, Rosalía recibió el premio a la mejor estrella emergente del 2019. El discurso tras la recogida del premio tuvo un toque reivindicativo y feminista, donde aseguró que no pararía "hasta que vea el mismo número de hombres y mujeres en el estudio" (Playz, 2019). La fotografía publicada en su Instagram también fue recibida como un acto de acercamiento al colectivo trans, ya que la actriz Hunter Schafer es transexual e icono de la comunidad LGTBI+ (La Vanguardia, 2019).

\section{Discusión y conclusiones}

El análisis realizado permite afirmar que Rosalía es un ejemplo tipo de "celebritizacion" que adopta la lógica mediática de las redes sociales, para construir su identidad, auto presentarse y dotar su identidad del contenido de una marca. Usa sus publicaciones para establecer relaciones con otras 
celebridades estableciendo estrategias de co-branding que le permiten darse a conocer a nuevos públicos, así como para presentar ideas y valores.

En relación con el primer objetivo de la investigación (O1), el análisis descriptivo de la actividad de Rosalía en Instagram evidencia que la artista aprovecha las potencialidades comunicativas de la red social (Seibel, 2019). Publica tanto imágenes como vídeos, a menudo de manera combinada, y recurre frecuentemente al texto y los emoticonos en los pies de foto, así como a las etiquetas y menciones para conectar con otros usuarios. La mayoría de sus publicaciones está relacionada con la moda, seguida por las publicaciones acerca de sus conciertos y premios y aquellas en las que aparece junto a sus amigos y otras celebridades. Por su parte, los selfies y los posts en los que promociona sus videoclips, la promoción de productos y publicaciones sobre activismo y colaboraciones con entidades aparecen en menor medida. Esta variada actividad digital alimenta su popularidad $\mathrm{y}$ el engagement de sus seguidores, constituyendo un buen ejemplo de "presencia social" de una celebridad (Biocca et al., 2003).

Por otro lado, el análisis semiótico visual de las publicaciones con más engagement en el perfil de Rosalía ha permitido identificar los referentes culturales a través de los que la cantante se dirige a su audiencia (O2), teniendo en cuenta el contexto en el que se encontraba, la cultura a la que hace referencia, y la identidad que construye en sus fotografías a partir de su indumentaria (Rodríguez, 2017).

Por lo que se refiere al contexto social, el espacio en el que se presenta Rosalía está marcado por un entorno internacional y globalizado. Mantiene el español como lengua principal para dirigirse a su audiencia en los pies de foto, al tiempo que publica posts acompañada de otros artistas, haciendo notar su integración en la industria de la música internacional. De este análisis, se puede observar cómo Rosalía no solo vende su música, sino también su identidad y todo el universo que le representa.

La construcción de su estética nos introduce en el ámbito de la cultura (segundo factor de análisis iconológico) en la que se enmarca Rosalía, ya que la artista dirige sus esfuerzos a participar de la cultura a través de su indumentaria. Rosalía representa la moda ratchet, un estilo urbano relacionado con el hip hop popularizado en los años 90 y que hoy en día está emparejado con el trap: "Es un estilo que ha alcanzado popularidad debido al aporte de numerosas cantantes femeninas como: Rosalía, Nathy Peluso, Billie Ellish, Lazowi y Cazzu, quienes en consecuencia a su labor como artistas han transformado esta tendencia en un estilo de vestir característico y ligado a su identidad artística" (Uria, 2019, p. 3). Este estilo promueve no solo la comodidad a través del uso de prendas deportivas, sino una expresión identitaria auténtica y original. Rosalía afirma que, desde la industria de la música, quiere visibilizar y reivindicar la figura de una mujer con poder (Sotillo, 2019). También su disco El Mal Querer se ha considerado un alegato contra el machismo y el amor tóxico, y a Rosalía como una abanderada del empoderamiento femenino (Espino, 2018). Los paralelismos creados en el imaginario de la artista con Frida Kahlo se encuentran en esta dirección (Ferrero, 2019).

Por lo que se refiere a su identidad como tercer factor de análisis iconológico, Rosalía ha equilibrado el estilo de la moda urbana con el universo de inspiración flamenca. Los encajes, volantes, flecos, lunares y los colores blanco, negro y rojo como predilectos, aparecen mezclados con el chándal, las zapatillas deportivas con plataforma, prendas exuberantes y nail art. También se observa una ambivalencia a la hora de presentarse ante sus seguidores: mientras en algunas publicaciones decide mostrarse con una actitud de empoderamiento femenino e incluso de forma agresiva o sensual, en consonancia con la cultura de la moda ratchet; en otras publicaciones muestra una cara risueña, sonriente o infantil.

La auto presentación de Rosalía entremezcla las tres categorías de formación de la identidad en las redes sociales (Marshall, 2015). La presentación del yo público, que consiste en la versión profesional 
de la artista, engloba todas aquellas publicaciones relacionadas con sus videoclips y conciertos; el yo público-privado, donde Rosalía construye su identidad, se presenta en sus publicaciones de vida cotidiana, los selfies o fotos con sus amigos; y, por último, el yo íntimo transgresor, puede verse en las publicaciones donde Rosalía expone sus ideas y pensamientos de forma intercomunicativa, como en las stories de su perfil respondiendo al análisis de El Mal Querer del youtuber Jaime Altozano.

Por último, el perfil en Instagram de Rosalía se adecua a las características de la "celebritización" de las que habla Driessens (2013). En el caso de la cantante catalana, podemos ver que no se limita a promocionar su música y su estilo de vida a través de los medios tradicionales, sino que también genera contenido para sus redes sociales como una manera de afianzar su marca personal. Otro indicador del impacto social y cultural que genera su perfil puede encontrarse en su diversificación. Rosalía se ha desplazado hacia el terreno de la moda a través de colaboraciones con marcas como Nike y Pull \& Bear, y también a través del merchandising y ropa de la marca "ROSALÍA". Al mismo tiempo, también se aprecia en su caso el proceso mediante el cual las celebridades utilizan su personalidad pública para desarrollar otras actividades profesionales. Esta "migración" de Rosalía se refleja en su participación como actriz en la película Dolor y Gloria, del director español Pedro Almodóvar.

Este trabajo pretende contribuir a los estudios sobre mediatización, evaluando el fenómeno emergente de la cantante Rosalía a través de su auto-presentación y relaciones con otras celebridades en la red social Instagram. En futuras investigaciones sería interesante enriquecer el trabajo sobre la imagen de Rosalía a través de un análisis de Twitter y YouTube, de tal forma que se pueda poner en relación las redes de influencia de la cantante, las letras y la simbología de los videoclips con la auto-presentación que se ha examinado en su perfil de Instagram. También se podría comparar la adaptación de Rosalía a la lógica de los medios sociales con respecto a otras celebridades contemporáneas. Finalmente, para conocer mejor el grado de influencia real de la artista como prescriptora de estilo de vida e imagen pública (más allá de los indicadores cuantitativos digitales), se podría ahondar en la percepción de los fans, a través de un análisis de los comentarios que dejan a sus publicaciones o por medio de grupos focales donde ahondar en las actitudes y opiniones de sus seguidores.

\section{Bibliografía}

Abidin, C. (2018). Internet Celebrity: Understanding Fame Online. Emerald Publishing.

Altheide, D. \& Snow, R. (1979). Media Logic. Sage.

Altozano, J. (2018, 9 de noviembre) ROSALÍA, lo que nadie está diciendo sobre "El mal querer" [video]. YouTube. https://www.youtube.com/watch?v=NgHXFTgaVT0

Andrés, L. (2019, 3 de julio). ¿Por qué el fenómeno Rosalía deja huella? La Vanguardia. https:// www.lavanguardia.com/economia/innovacion/20190703/463279340697/por-que-fenomenorosalia-deja-huella.html

Antena 3 Noticias (2020, 5 de mayo). La foto de Rosalía subida de tono que revoluciona Instagram durante el confinamiento por coronavirus. https:/www.antena3.com/noticias/cultura/ foto-rosalia-subida-tono-que-revoluciona-fans-famosos-instagram-confinamiento-coronavirus 20 $\underline{2005045 \mathrm{eb} 0 \mathrm{f} 40380 \mathrm{~b} 64600010 \mathrm{~d} 1891 . \mathrm{html}}$

Ballesteros-Herencia, C. A. (2019). La representación digital del engagement: Hacia una percepción del compromiso a través de acciones simbólicas. Revista de Comunicación, 18(1), 215-233. https://doi.org/10.26441/RC18.1-2019-A11 
Basilisco, R., Amenuvor, F.E., Owusu-Antwi, K. \& Hyeok, C.J. (2019). Celebrity Self-disclosure and Social Cohesion Perspectives from Ghanaian Instagram Users. Current Journal of Applied Science and Technology, 38(5), 1-19.

Biocca, F., Harms, C., \& Burgoon, J. K. (2003). Toward a more robust theory and measure of social presence: Review and suggested criteria. Presence: Teleoperators \& virtual environments, 12(5), 456-480.

Bucher, T., \& Helmond, A. (2018). The Affordances of Social Media Platforms. In J. Burgess, A. Marwick, \& T. Poell (Eds.), The SAGE Handbook of Social Media (pp. 233-253). Sage.

Casero-Ripollés, A., Feenstra, R. \& Tormey, S. (2016). Old and New Media Logics in an Electoral Campaign: The Case of Podemos and the Two-Way Street Mediatization of Politics. The International Journal of Press/Politics. https://doi.org/10.1177/1940161216645340.

Chadwick, A. (2013). The Hybrid Media System. Politics and Power. Oxford University Press.

Chocano, C. (2020, 22 de junio). Rosalía: ella manda. Elle. https://www.Elle.com/es/living/ociocultura/a32930669/entrevista-rosalia-Elle-julio/

Courtés, J. (1997). Análisis Semiótico del Discurso. Editorial Gredos.

Díez, N. (2020, 19 de enero). LA ROSALÍA: Un marketing CON ALTURA (Análisis: Lo que nadie te dice) [vídeo]. YouTube. https://www.youtube.com/watch?v=tzbrKBv-khE

Driessens, O. (2013). The celebritization of society and culture: understanding the structural dynamics of celebrity culture, International Journal of Cultural Studies, 16(6): 641-57.

El Corte Inglés (s.f.). Icons in the making. https://www.elcorteingles.es/deportes/nike/am90-rosalia/

El País. (2020, 20 de mayo). Rosalía, desde su confinamiento en Miami: "Es como si el mundo se hubiese parado". https://elpais.com/gente/2020-05-20/rosalia-desde-su-confinamiento-en-miamies-como-si-el-mundo-se-hubiese-parado.html

Espino, A. (2018, 8 de noviembre). El alegato de Rosalía contra el machismo. Ethic. https://ethic. es/2018/11/rosalia-alegato-contra-machismo/

Ferrero, C. (2019, 25 de junio). ¿Un chándal de Louis Vuitton hecho con una toalla? La historia detrás del look favorito de Rosalía. S Moda. https://smoda.elpais.com/moda/actualidad/rosaliachandal-louis-vuitton-toallas-playa/

Ferrero, C. (2019, 8 de noviembre). Entrecejo a lo Frida Kahlo y dientes de oro: las referencias escondidas en el último vídeo de Rosalía. S Moda. https://smoda.elpais.com/moda/actualidad/ entrecejo-a-lo-frida-kahlo-y-dientes-de-oro-las-referencias-escondidas-en-el-ultimo-video-de-rosalia/

Gamboa, M. (2020, 16 de febrero). Rosalía es criticada por supuesto parecido con Kylie Jenner. Show. https://www.show.news/music/Rosalia-es-criticada-por-supuesto-parecido-con-KylieJenner-20200216-0012.html

Gamson, J. (1992). The assembly line of greatness: celebrity in twentieth-century America. Critical Studies in Mass Communication, 9(1): 1-24.

Hiller, R.S. (2016). Sales displacement and streaming music: Evidence from YouTube. Information Economics and Policy, 34, 16-26.

Hjarvard, S. (2013). The mediatization of culture and society. Routledge. 
Kim J. \& Song H. (2016). Celebrity's self-disclosure on Twitter and parasocial relationships: A mediating role of social presence. Computers in Human Behavior; 62: 570-577.

Klinger, U. \& Svensson, J. (2015). Network Media Logic. En Bruns, A., Enli, G., Skogerbo, E., Larsson, A. O., \& Christensen, C. (Eds.). The Routledge Companion to Social Media and Politics (pp. 23-38). Routledge.

La Vanguardia (2019, 19 de diciembre). La foto de Instagram con la que Rosalía se acerca al colectivo trans. https://www.lavanguardia.com/muyfan/20191219/472357734061/rosalia-hunterschafer-instagram-foto-trans.html

Lázaro, S. (2020, 12 de enero). Rosalía y Kylie Jenner dan un paso más en su 'relación'. Vogue. https://www.vogue.es/celebrities/articulos/rosalia-kylie-jenner-instagram-juntas

Lewis, T. (2010). Branding, celebritization and the lifestyle expert. Cultural Studies, 24(4): 580-598.

Livingstone, S. (2009). On the Mediation of Everything: ICA Presidential Address 2008. Journal of Communication, 59 (1): 1-18. https://doi.org/10.1111/j.1460-2466.2008.01401.x

Lundby, K. (2014). Mediatization of communication. En Lundby, K. (Ed.). Mediatization of communication (pp. 3-35). De Gruyter Mouton.

Marshall, P. D. (2010). The promotion and presentation of the self: Celebrity as marker of presentational media, Celebrity Studies, 1(1): 45.

Martíns, P. (2020a, 12 de enero). Rosalía y Kylie Jenner vuelven a verse y comparten una fotografia juntas en Instagram. Harper's Bazaar. https://www.harpersbazaar.com/es/cultura/ocio/ a30484270/rosalia-kylie-jenner-fotografia-juntas-instagram/

Martíns, P. (2020b, 3 de mayo). La camisa de Rosalía que te hará soñar con pasear por el campo. Harper's Bazaar. https://www.harpersbazaar.com/es/moda/noticias-moda/a32354649/rosaliacamisa-jacquemus/

Mattei, M. M. (2014). El divismo en tiempos de Instagram. Cuadernos de Información y Comunicación, 20, 95-107.

Montells, L. (2018) Qué es el engagement en instagram y cómo puede ayudarte. Metricool. https://metricool.com/es/que-es-el-engagement-en-instagram-y-como-puede-ayudarte/

Muñoz, S. (2020, 10 de julio). Rosalía se convierte en la nueva embajadora de Nike. Harper's Bazaar. https://www.harpersbazaar.com/es/moda/noticias-moda/a33270417/rosalia-nueva-imagennike-air-max-video-viral-instagram/

Navarro, F. (2018, 2 de noviembre). El fenómeno paranormal de Rosalía aterriza en Madrid. El País. Recuperado de https://elpais.com/cultura/2018/10/31/actualidad/1540989815_414338.html

Nigramercato (2019, 14 de agosto). Cultura bootleg, más allá de la copia. https://nigramercato. com/es/blog/cultura-bootleg-mas-alla-de-la-copia-n8

Panofsky, E. (2005). Estudios sobre Iconografia. Editorial Alianza.

Pérez, M. J. (2017, 21 de noviembre). La nueva pose que está por todo Instagram tiene una razón de ser. Vogue España. https://www.vogue.es/living/articulos/tendencias-instagram-pose-cuclillas/31965

Personalitia (2019, 27 de agosto). ¿En qué consiste la corriente 'Athleisure'?. https://personalitia. com/2019/08/27/en-que-consiste-la-corriente-athleisure/ 
Playz (2019, 13 de diciembre). Rosalía, reivindicativa en los premios Women in music de Billboard: "No pararé hasta que vea el mismo número de hombres y mujeres en el estudio". https://www. rtve.es/playz/20191213/rosalia-reivindicativa-premios-women-in-music-billboard-no-parare-hasta-vea-mismo-numero-hombres-mujeres-estudio/1993698.shtml

Rodríguez, R. (2017). Semiótica del mural: "Desde la creación del hombre Kolla" de la municipalidad provincial de Puno [tesis inédita de licenciatura, Universidad Nacional del Altiplano]. Repositorio Institucional. http://repositorio.unap.edu.pe/handle/UNAP/4939

Seibel, B. (2019). Insta-Identity: the Construction of Identity through Instagram an Extended Literature Review. University Honors Theses. https://doi.org/10.15760/honors.764

Sotillo, M. (2019, 5 de enero). Rosalía: "Prefiero el oro a la plata, el chándal a los vaqueros y las uñas largas a las cortas”. Yo Dona. https://www.elmundo.es/yodona/celebrities/2019/01/05/5c2cb45efdddffeb378b458f.html

Stepanyan, A. (2019). New Media Literacy: celebrity worship, Instagram and self-esteem [tesis inédita de maestría, California State University]. Repositorio institucional. http://csus-dspace.calstate.edu/handle/10211.3/213004

Turner, G. (2004). Understanding Celebrity. Sage.

Turner, G. (2006). The mass production of celebrity. 'celetoids', reality tv and the 'demotic turn', International Journal of Cultural Studies, 9(2): 153-165.

Uria, M. (2019). Moda Ratchet. Combinación de disciplinas artísticas en la generación de un estilo [Trabajo Fin de Grado, Universidad de Palermo]. Repositorio institucional. https://fido.palermo. $\underline{\text { edu/servicios_dyc/catalogo de proyectos/detalle_proyecto.php?id_proyecto }=5513}$

Van Dijck, J. (2013). The culture of connectivity: A critical history of social media. Oxford University Press.

Van Dijck, J. \& Poell, T. (2013). Understanding Social Media Logic. Media and Communication, 1(1), 2-14.

We are Social \& Hootsuite (2021). Digital 2021 Global Overview Report https://datareportal.com/ reports/digital-2021-global-overview-report

Zulli, D. (2017). Capitalizing on the look: insights into the glance, attention economy, and Instagram. Critical Studies in Media Communication, 35(2), 137-150. https://doi.org/10.1080/1529503 6.2017 .1394582 